\title{
The Contribution of Pollen Germination Rates to Uneven Paternity Among Polycrosses of Cryptomeria japonica
}

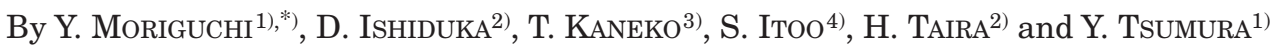

(Received 22 ${ }^{\text {th }}$ August 2008)

\begin{abstract}
Polycrossing is a very useful and cost-effective approach when designing mating trials. However, since the maternal general combining ability (GCA) in polycross designs is estimated on the assumption of equal contributions from paternal parents; any unequal paternal contribution leads to biased GCA estimates. Progeny from polycrossing Cryptomeria japonica, in which three mixtures from three paternal donors were crossed with each of three maternal parents, were analyzed using microsatellite markers to detect departures from equal paternal contribution. The deviations from equal paternal contribution were evaluated using a $\chi^{2}$ goodness of fit test. In this test, we examined the null hypothesis of equal paternal contribution for each mother tree. Two different methods were used to calculate paternal contribution: first, simply the number of seeds produced by each male parent, and second, the number of seeds produced by each male parent weighted according to the proportion of full seeds in single cross. The results of the $\chi^{2}$ test showed that the contribution to seed production by each paternal clone differed significantly in all polycrosses. The average pollen germination rate was significantly different between paternal clones. The contribution of each pollen donor in a polycross was related to their pollen germination rate.
\end{abstract}

Key words: Male reproductive success, Paternal success, GCA, Molecular marker, Polymixes.

\section{Introduction}

Polycrossing is one of the mating designs employed to create progeny populations for genetic testing (ZOBEL and TALBERT, 1984). In polycross designs, mixtures containing pollen from many male parents are used in the controlled cross. Therefore for a particular offspring, although the maternal parent is known, the paternal parent is unknown. The advantage of polycross designs is that they are inexpensive and require little labor. However, because the paternal parent is unknown, it is not possible to estimate the general combining ability (GCA) of the paternal parent. Estimates of the maternal

1) Department of Forest Genetics, Forestry and Forest Products Research Institute, Tsukuba, Ibaraki 305-8687, Japan.

2) Graduate School of Science and Technology, Niigata University, Igarashi 2-nocho, Niigata, 950-2101, Japan.

3) Niigata Prefectural Itoigawa Region Agriculture and Forestry Office, 1-15-1 Minamioshiage, Itoigawa, Niigata 941-0052, Japan.

4) Niigata Prefectural Forest Research Institute, 2249-5 Unotoro, Murakami, Niigata 958-0264, Japan.

*) Corresponding author: Yoshinari MoRiguchi. Department of Forest Genetics, Forestry and Forest Products Research Institute, Tsukuba, Ibaraki 305-8687, Japan. Tel: 029-829-8261; Fax: 029-874-3720. E-Mail: chimori@ffpri.affrc.go.jp
GCA from polycross designs assume equal contribution by paternal parents. Any unequal paternal contribution in polycross designs leads to biased maternal GCA estimates. The majority of studies have shown that paternal contributions in controlled polycross trials are unequal; this has been demonstrated for Populus spp. (WheEler et al., 2006), Betula pendula (PASONEN et al., 1999), Pinus radiata (Moran and Grifin, 1985), Picea mariana (Rogers and BoYle, 1991), Picea abies (SCHOEN and Cheliak, 1987; Skrøppa and Lindgren, 1994; ARONEN et al., 2002) and Pseudotsuga menziesii (APsIT et al., 1989; NAKAMURA and WhEELER, 1992). A few studies have demonstrated equal paternal contributions in species including Pinus taeda (WISELOGEL and VAN BuiJTEnen, 1988) and Chamaecyparis obtusa (SEIDO et al., 2000).

Sugi (Cryptomeria japonica) is an allogamous, windpollinated conifer species; it is an important commercial forest tree in Japan. Seeds of high genetic quality and diversity are produced in seed orchards. A previous gene flow study in a $C$. japonica seed orchard identified the relatively high paternal contribution of clone 53 to the pollination of clone 6 (accounting for about $64 \%$ of its total fertilization) (MoRIGUCHI et al., 2007). However, it is not possible to conclude, from existing studies, whether differential paternal contribution occurs in C. japonica. Though there are two previous reports that investigated whether paternal contributions in polycrosses are equal using Wogon-Sugi, a chlorophyll-deficient mutant (OHBA et al., 1971) with incomplete paternal inheritance, the conclusions are different between them (OнвA, 1972; ITOYA, 1978).

Therefore, the aim of present study was to investigate whether paternal contributions in polycross offspring are unequal. We used microsatellite markers, a powerful molecular tool for determining parentage. We also studied whether the in vitro pollen germination rate corresponds to the proportion of seeds sired by each pollen donor.

\section{Materials and Methods}

\section{Pollen collection and pollen germination tests}

In February 2004, pollen from nine clones was collected from the $C$. japonica clone orchard archive located at the Niigata Prefectural Forest Research Institute. Pollen was stored in dry conditions in a refrigerator at $4{ }^{\circ} \mathrm{C}$ for one month. Pollen collected from each of nine clones was germinated. Each germination test was replicated three times. Pollen grains were germinated on $1 \%$ agar containing $5 \%$ sucrose, in Petri dishes under standard conditions, i.e. $96 \mathrm{~h}$ at $25^{\circ} \mathrm{C}$ in the dark as 
described by SAITO and YAMAMOTO (1977). Germination was terminated by staining the pollen with a lactic phenol-cotton blue, after which the samples were transferred onto glass slides. The germination percentage was determined by counting more than 600 randomly selected pollen grains per sample. We defined the germination of pollen grains as having occurred when the length of the pollen tube was at least half of the diameter of the pollen grain.

\section{Experimental material produced by pollination}

Pollen mixtures were prepared by combining equal weights of desiccated pollen from three clones. The compositions of the three pollen mixtures are shown in Table 1. The polycross was conducted using a mixture of pollen from three clones; a single-cross for each clone was also made (Table 1). Each cross was repeated on three grafts from each maternal clone. Before the flowers reached maturity, we removed the male ones and

Table 1. - Summary of pollination results, including nine polycrosses and 27 single crosses.

\begin{tabular}{|c|c|c|c|c|}
\hline $\begin{array}{c}\text { Maternal } \\
\text { parent }\end{array}$ & Paternal parents & $\begin{array}{c}\text { Rate of Cone set } \\
(\%)\end{array}$ & $\begin{array}{c}\text { Number of seeds } \\
\text { per cone }\end{array}$ & $\begin{array}{c}\text { Proportion of full } \\
\text { seeds }(\%)\end{array}$ \\
\hline $\mathrm{C} 5$ & $\begin{array}{l}\text { Pollen mixture } 1 \\
\text { (C29, C67, C75) }\end{array}$ & $95.4(+4.0)$ & $58.6( \pm 4.7)$ & $37.0(+7.4)$ \\
\hline $\mathrm{C} 5$ & $\mathrm{C} 29$ & $84.0( \pm 14.5)$ & $63.6( \pm 2.6)$ & $34.3( \pm 10.9)$ \\
\hline $\mathrm{C} 5$ & $\mathrm{C} 67$ & $84.1( \pm 15.7)$ & $58.0( \pm 8.9)$ & $31.0( \pm 3.1)$ \\
\hline $\mathrm{C} 5$ & $\mathrm{C} 75$ & $80.1( \pm 15.5)$ & $61.5( \pm 1.6)$ & $38.7( \pm 5.2)$ \\
\hline C38 & $\begin{array}{l}\text { Pollen mixture } 1 \\
(\mathrm{C} 29, \mathrm{C} 67, \mathrm{C} 75)\end{array}$ & $94.2( \pm 6.6)$ & $71.3( \pm 14.3)$ & $42.2( \pm 9.3)$ \\
\hline C38 & $\mathrm{C} 29$ & $43.5( \pm 8.2)$ & $74.5(+7.8)$ & $52.3( \pm 4.3)$ \\
\hline C38 & C67 & $97.8( \pm 3.8)$ & $73.3( \pm 7.8)$ & $36.2( \pm 10.6)$ \\
\hline C38 & $\mathrm{C} 75$ & $86.2( \pm 17.6)$ & $68.6( \pm 11.3)$ & $32.4( \pm 4.0)$ \\
\hline C65 & $\begin{array}{l}\text { Pollen mixture } 1 \\
(\mathrm{C} 29, \mathrm{C} 67, \mathrm{C} 75)\end{array}$ & $86.2( \pm 17.4)$ & $41.3( \pm 19.0)$ & $55.3( \pm 7.1)$ \\
\hline C65 & $\mathrm{C} 29$ & $79.0( \pm 25.2)$ & $46.1( \pm 24.4)$ & $67.1( \pm 9.5)$ \\
\hline C65 & C67 & $93.5( \pm 8.6)$ & $63.7( \pm 8.3)$ & $44.8(+11.6)$ \\
\hline C65 & $\mathrm{C} 75$ & $96.6( \pm 4.0)$ & $57.6( \pm 18.2)$ & $42.8( \pm 13.6)$ \\
\hline $\mathrm{C} 6$ & $\begin{array}{c}\text { Pollen mixture } 2 \\
\text { (C5, C37, C53) }\end{array}$ & $96.5( \pm 4.1)$ & $33.9( \pm 6.5)$ & $30.6( \pm 7.1)$ \\
\hline $\mathrm{C} 6$ & $\mathrm{C} 5$ & $95.5( \pm 7.9)$ & $48.3( \pm 2.9)$ & $23.6( \pm 6.2)$ \\
\hline $\mathrm{C} 6$ & $\mathrm{C} 37$ & $98.5( \pm 3.4)$ & $50.2( \pm 8.5)$ & $41.3( \pm 8.0)$ \\
\hline $\mathrm{C} 6$ & $\mathrm{C} 53$ & $99.5( \pm 0.9)$ & $44.9( \pm 1.9)$ & $26.8( \pm 1.3)$ \\
\hline C44 & $\begin{array}{c}\text { Pollen mixture } 2 \\
\text { (C5, C37, C53) }\end{array}$ & $89.4( \pm 12.9)$ & $20.5( \pm 3.4)$ & $47.3( \pm 5.1)$ \\
\hline $\mathrm{C} 44$ & $\mathrm{C} 5$ & $94.7( \pm 6.2)$ & $28.9( \pm 4.5)$ & $37.0( \pm 10.4)$ \\
\hline $\mathrm{C} 44$ & $\mathrm{C} 37$ & $98.6( \pm 2.5)$ & $35.2( \pm 3.7)$ & $43.3( \pm 4.6)$ \\
\hline $\mathrm{C} 44$ & C53 & $90.0( \pm 8.7)$ & $21.3( \pm 4.6)$ & $42.8( \pm 4.4)$ \\
\hline C60 & $\begin{array}{l}\text { Pollen mixture } 2 \\
\text { (C5, C37, C53) }\end{array}$ & $98.9( \pm 2.0)$ & $47.9( \pm 5.2)$ & $41.1( \pm 11.2)$ \\
\hline $\mathrm{C} 60$ & $\mathrm{C} 5$ & $92.1( \pm 10.4)$ & $35.6( \pm 12.1)$ & $33.9( \pm 4.4)$ \\
\hline $\mathrm{C} 60$ & $\mathrm{C} 37$ & $98.6( \pm 1.2)$ & $57.2( \pm 12.1)$ & $54.3( \pm 5.5)$ \\
\hline C60 & C53 & $98.9( \pm 1.9)$ & $48.5( \pm 21.7)$ & $50.3( \pm 2.4)$ \\
\hline C52 & $\begin{array}{c}\text { Pollen mixture } 3 \\
(\mathrm{C} 9, \mathrm{C} 58, \mathrm{C} 63)\end{array}$ & $77.7( \pm 24.3)$ & $25.1( \pm 9.0)$ & $15.7( \pm 15.0)$ \\
\hline $\mathrm{C} 52$ & $\mathrm{C} 9$ & $75.8( \pm 30.6)$ & $23.6( \pm 2.5)$ & $15.5( \pm 6.0)$ \\
\hline C52 & C58 & $77.6( \pm 14.2)$ & $21.5( \pm 3.7)$ & $23.3( \pm 4.9)$ \\
\hline $\mathrm{C} 52$ & $\mathrm{C} 63$ & $81.1( \pm 5.4)$ & $20.7( \pm 4.1)$ & $17.8( \pm 5.1)$ \\
\hline $\mathrm{C} 27$ & $\begin{array}{c}\text { Pollen mixture } 3 \\
\text { (C9, C58, C63) }\end{array}$ & $91.8( \pm 7.4)$ & $46.6( \pm 15.8)$ & $24.1( \pm 4.6)$ \\
\hline $\mathrm{C} 27$ & $\mathrm{C} 9$ & $96.1( \pm 2.3)$ & $34.0(+7.6)$ & $27.6( \pm 8.8)$ \\
\hline $\mathrm{C} 27$ & C58 & $93.2(+9.6)$ & $27.4(+2.5)$ & $44.1(+3.5)$ \\
\hline $\mathrm{C} 27$ & $\mathrm{C} 63$ & $93.4( \pm 9.6)$ & $36.4( \pm 5.5)$ & $37.3( \pm 2.8)$ \\
\hline C54 & $\begin{array}{c}\text { Pollen mixture } 3 \\
(\mathrm{C} 9, \mathrm{C} 58, \mathrm{C} 63)\end{array}$ & $93.8( \pm 5.5)$ & $25.6( \pm 5.8)$ & $32.7( \pm 6.9)$ \\
\hline C54 & $\mathrm{C} 9$ & $87.5( \pm 13.0)$ & $27.6( \pm 5.1)$ & $41.3( \pm 5.5)$ \\
\hline C54 & C58 & $91.3( \pm 11.3)$ & $26.3( \pm 5.0)$ & $37.4( \pm 6.3)$ \\
\hline C54 & C63 & $96.7( \pm 1.1)$ & $25.4( \pm 5.4)$ & $37.0( \pm 1.0)$ \\
\hline
\end{tabular}


isolated the female ones using paper breeding bags. At the peak of receptivity, in March, we pollinated the appropriate clones. Each graft was pollinated twice (on two days). The breeding bags were removed in May, and the number of pollinated female flowers on each graft was counted. The mature cones were harvested in October, and the number from each graft was recorded. The rate of cone set for each graft was defined as the ratio of the number of mature cones in October to the number of pollinated female flowers in May. We extracted the seed from the cones, and counted the number produced, per cone, for each graft. Three hundred seeds were selected randomly from each graft and X-rayed (SOFTEX-EMB, Tokyo, Japan) to determine the proportion of full seeds.

\section{DNA extraction and microsatellite genotyping}

We collected needles from all clones that were used in the pollination trials. The total DNA was extracted from the needles using the modified CTAB method (TSUMURA et al., 1995). Seeds used for the X-ray analysis were sown on sterile paper on plastic plates, and DNA was extracted from germinated embryos using the CTAB method (MurRAY and THOMPSON, 1980). We used more than 90 seeds per polycross for DNA extraction, except for the two polycrosses, C52 x pollen mixture 3 and C54 $x$ pollen mixture 3 , which had produced few female flowers (Table 2). These two polycrosses were excluded from the subsequent analysis.
We used four microsatellite markers that exhibited high stability and polymorphism (Table 3; MoRIGUCHI et al., 2003 and TANI et al., 2004) to determine the pollen donors and pollen contamination rates for seeds produced from the nine polycrosses. PCR amplifications were performed using Model 9600 and 9700 GeneAmp PCR Systems (Applied Biosystems). In each case a total volume of $10 \mu \mathrm{L}$ was used, containing $20 \mathrm{mM}$ Tris-HCl ( $\mathrm{pH} 8.0$ ), $50 \mathrm{mM} \mathrm{KCl}, 1.5 \mathrm{mM}$ of $\mathrm{MgCl}_{2}, 0.16 \mathrm{mM}$ of each dNTP, $0.2 \mu \mathrm{M}$ of each primer, $5 \mathrm{ng}$ of template DNA, and 0.625 units of Taq polymerase (PROMEGA). The PCR program consisted of: $5 \mathrm{~min}$ denaturation at $94{ }^{\circ} \mathrm{C}$, followed by $30-35$ cycles of $30 \mathrm{sec}$ denaturation at $94^{\circ} \mathrm{C}$, $30 \mathrm{sec}$ annealing at $60^{\circ} \mathrm{C}$, and $30 \mathrm{sec}$ extension at $72^{\circ} \mathrm{C}$, with a final extension step of $72^{\circ} \mathrm{C}$ for 5 min. Genotypes of the paternal candidate $C$. japonica trees and the offspring from each polycross, based on the microsatellite markers, were determined using ABI prism 3100 genetic analyzers (Applied Biosystems).

\section{Data analysis}

From the genotype data for the paternal candidates, we calculated the paternity exclusion probability for each locus and the multi-paternity exclusion probability (WEIR, 1996) using the G-DIVERSE software developed by Hiroyoshi Iwata (NARC, Tsukuba, Japan). We determined the paternal parent of each of the germinated seeds after excluding pollen contamination and self-fer-

Table 2. - Number of offspring assigned to each paternal parent in the polycross and the pollen germination rate of each paternal parent. The two pollinations, C52 x pollen mixture3 and C54 x pollen mixture3, were excluded because the number of seeds produced was too low to analyze statistically. For each combinations, the relationship between the pollen germination rate and paternal contribution was examined by Spearman rank correlation test.

\begin{tabular}{|c|c|c|c|c|c|c|c|c|c|c|}
\hline & C5 $\times \mathrm{PMl}^{a}$ & C38 x PM1" & C65 $x \mathrm{PMI}^{\mathrm{a}, * \cdots}$ & $\mathrm{C} 6 \times \mathrm{PM}^{\mathrm{h}}$, * & $\mathrm{C} 44 \times \mathrm{PM} 2^{\mathrm{h} . \mathrm{x}}$ & 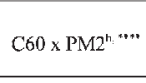 & $\mathrm{C} 52 \times \mathrm{PM}^{\circ}$ & 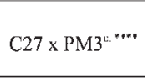 & $\mathrm{C} 54 \times \mathrm{PM}^{\mathrm{E}}$ & $\begin{array}{c}\text { Average pollen } \\
\text { germination rate } \\
(\%) \\
\end{array}$ \\
\hline $\mathrm{C} 29$ & 120 & 127 & 63 & - & - & - & - & - & - & $73.5( \pm 4.7)$ \\
\hline C67 & 21 & 29 & 17 & - & - & - & - & - & - & $40.9( \pm 4.9)$ \\
\hline C75 & 42 & 35 & 10) & - & - & - & - & - & - & $38.1( \pm 8.7)$ \\
\hline C5 & - & - & - & 22 & 28 & 30 & - & - & - & $53.4( \pm 10.0)$ \\
\hline C37 & - & - & - & 87 & 71 & 90 & - & - & - & $68.7( \pm 13.6)$ \\
\hline $\mathrm{C} 53$ & - & - & - & 29 & 39 & 55 & - & - & - & $59.7( \pm 11.8)$ \\
\hline $\mathrm{Cg}$ & - & - & - & - & - & - & 3 & 23 & 4 & $52.0( \pm 8.6)$ \\
\hline C58 & - & - & - & - & - & - & 15 & 28 & 16 & $61.9( \pm 13.6)$ \\
\hline $\mathrm{C} 63$ & - & - & - & - & - & - & 11 & 50 & 4 & $68.5( \pm 5.6)$ \\
\hline Self-fertilization & 8 & 3 & 0 & 0 & 3 & 0 & 0 & 0 & 0 & - \\
\hline Contamination & 0 & 0 & 0 & 0 & 41 & 0 & 0 & 0 & 1 & - \\
\hline Total & 191 & 194 & 90 & 138 & 182 & 175 & 29 & 101 & 25 & - \\
\hline
\end{tabular}

a PM1 refers to pollen mixture 1 including the pollen from $\mathrm{C} 29, \mathrm{C} 67$ and $\mathrm{C} 75$.

${ }^{\mathrm{b}} \mathrm{PM} 2$ refers to pollen mixture 2 including the pollen from C5, C37 and C53.

c PM3 refers to pollen mixture 3 including the pollen from $\mathrm{C} 9, \mathrm{C} 58$ and $\mathrm{C} 63$.

$* * * *, \mathrm{P}<0.001$

Table 3. - Microsatellite markers used in this study.

\begin{tabular}{lllll}
\hline \multicolumn{1}{c}{ primer } & \multicolumn{1}{c}{ motif } & \multicolumn{1}{c}{ Forward primer 5' to $3^{\prime}$} & \multicolumn{1}{c}{ Reverse primer 5 ' to $3^{\prime}$} & Q $^{{ }^{\prime}}$ \\
\hline Cjgssr 78 & $(\mathrm{GA})_{21}$ & AAGAAGGCATCCAAGAGTGA & ACTGCCGATTAACTGATAGCTC & 0,824 \\
Cs 1525 & $(\mathrm{CA})_{18}$ & ATGAAGTGCCCTTGGTTTGT & ATCGCCTCCTCTTTTATCCT & 0,843 \\
Cjgssr 175 & $(\mathrm{CT})_{16}$ & ACCCTTTGAATTATTCCTTGAG & AGCGGAAAAAACTACATCAGA & 0,688 \\
Cs 1219 & $(\mathrm{GT})_{10}$ & AAGGTGTTGTTTTAAGGAGG & CAGCCATCTATTATTTGTGC & 0,525 \\
\hline
\end{tabular}

${ }^{a}$ Multi-paternity exclusion probability $=0.996$. 
tilization, following the simple exclusion method of MoRiguchi et al. (2004). The deviations from equal paternal contribution were evaluated by a $\chi^{2}$ goodness of fit test, as follows. First, we examined the null hypothesis of equal paternal contribution for each mother tree using the formula EPC1 (see below). Second, we examined the null hypothesis of equal paternal contribution for each mother tree, weighted according to the proportion of full seeds in a single cross, using EPC2.

EPC1 $=($ total number of seeds $) / 3$

EPC2 $=($ total number of seeds $) \times[$ (the proportion of full seeds of $i$-th paternal clone) / (sum of the proportion of full seeds in the pollen mixture)].

Differences in the proportion of full seeds and the average pollen germination rate among clones were examined by one-way ANOVA. The relationship between the pollen germination rate and paternal contribution was examined by Spearman rank correlation test. These analyses were done using JMP4 software ver. 11.5 (SAS Institute Inc., Cary, N.C.).

\section{Results}

The multi-paternity exclusion probability (WEIR, 1996), determined on the basis of the four microsatellite markers, was high (0.996). This indicated that the level of genetic polymorphism was sufficient to identify all pollen donors in this study unambiguously; this was because the number of parents was limited (only 17 clones). In fact, these four microsatellite markers unambiguously determined the pollen donors for each cross.

The average rates of cone set were generally high in all crosses, suggesting that pollination was generally successful in this study (Table 1). Although the C38 $\mathrm{x}$ C29 cross produced a large proportion of immature cones, we were able to use seeds from this cross for further analysis because of the sufficiently high average number of seeds per cone. For single crosses, there was no difference in the rate of full seed (examined using ANOVA) between the three paternal parents, with the exception of mother trees C38 $(p<0.05)$, C6 $(p<0.01)$ and $\mathrm{C} 60(p<0.005)$. High contamination was detected in the $\mathrm{C} 44 \mathrm{x}$ pollen mixture no. 2 cross, and low rates of self-fertilization were detected in some crosses (Table 2).

In this study, we corrected the expected equal paternal contributions on the basis of the proportion of full seeds in single cross $\left(\mathrm{EPC}_{2}\right)$. The $\chi^{2}$ test for goodness-of-fit indicated that the null hypothesis, i.e. that every paternal clone contributed equally to seed production, should be rejected for all polycrosses (Table 4). The average pollen germination rate was $57.4 \%$, ranging from $38.1 \%$ to $73.5 \%$ for the different clones (Table 2), these differences were statistically significant (ANOVA, $p<0.0001$ ). The pollen germination rates were significantly related to paternal contribution in all combination except for C5 $x$ pollen mixture no. 1 cross and C38 $x$ pollen mixture no. 1 cross (Table 2). Even the two combinations that have no statistical significance, the paternal contributions tended to be associated with the pollen germination rates (Fig. 1).

\section{Discussion}

The rate of cone set was generally high for the control crosses in this study (Table 1), suggesting that the timing of pollination, as well as the quantity of pollen supplied, was appropriate. The significant difference, for some mother trees, in the proportion of full seeds produced by each of the three paternal parents used in the pollen mixture seemed to be related to the pollen germination rates (Table 1 , Table 2 ).

Paternal parentage was determined using four microsatellite loci. The high contamination detected in the $\mathrm{C} 44 \mathrm{x}$ pollen mixture no. 2 polycross could be the result of damage to breeding bags by snow, wind or birds (Table 2). Moreover, the low level of self-fertilization detected in some crosses might be explained by incomplete male flower removal before pollination. The significant deviation, in all polycrosses, from equal paternal contribution suggests that this is the general case in C. japonica. Similar results have been recorded previously in many forest tree species, as mentioned above.

The causes of unequal contribution have been studied in a large number of species. SNOw and SPIRA (1996), PASONEn et al. (1999) and ARONEn et al. (2002) reported that pollen-tube growth rate affects paternal contribution in Hibiscus moscheutos, Betula pendula and Picea abies, respectively. Moreover, SPIRA et al. (1996) reported that the timing of pollen arrival on the stigma affects paternal contribution in Hibiscus moscheutos. In addition, PARANTAinen and PASOnen (2004) found pollenpollen interactions in artificial crossing experiments using pollen mixtures in Pinus sylvestris. NAKAMURA and WHEELER (1992) reported that genetic incompatibility between male and female gametophytes affects paternal contributions in Pseudotsuga menziesii. In the current study, the average pollen germination rate was significantly different between clones and this difference seemed to influence the levels of the paternal contribu-

Table 4. - The chi-squared values of testing the null hypothesis of equal paternal contribution, based on seed number (EPC1) and seed number weighted on the basis of full seeds in single crosses (EPC2).

\begin{tabular}{|c|c|c|c|c|c|c|c|c|c|}
\hline & $\mathrm{C} 5 \times \mathrm{PM}^{\mathrm{a}}$ & $\mathrm{C} 38 \times \mathrm{PM}^{\mathrm{a}}$ & $\mathrm{C} 65 \times \mathrm{PM1}^{\mathrm{a}}$ & $\mathrm{C} 6 \times \mathrm{PM}^{\mathrm{h}}$ & $\mathrm{C} 44 \times \mathrm{PM}^{\mathrm{h}}$ & $\mathrm{C} 60 \times \mathrm{PM}^{\mathrm{b}}$ & $\mathrm{C} 52 \times \mathrm{PM}^{\circ}$ & $\mathrm{C} 27 \times \mathrm{PM}^{\circ}$ & $\mathrm{C} 54 \times \mathrm{PM}^{\circ}$ \\
\hline $\mathrm{EPC}_{1}\left(\chi^{2}\right)$ & $89.21^{* * * *}$ & $94.79^{* \pi * *}$ & $55.27^{x * * *}$ & $55.35^{* * * *}$ & $21.70^{* * * *}$ & $31.14^{* * * *}$ & - & $12.26^{* * * *}$ & - \\
\hline $\mathrm{EPC}_{2}\left(\chi^{2}\right)$ & $89.58^{* * * *}$ & $42.85^{* * * *}$ & $42.81^{=* * * *}$ & $18.26^{* * * x}$ & $16.45^{* * * *}$ & $11.67^{* * * *}$ & - & $14.15^{* * * *}$ & - \\
\hline
\end{tabular}

a PM1 refers to pollen mixture 1 including the pollen from C29, C67 and C75.

b PM2 refers to pollen mixture 2 including the pollen from C5, C37 and C53.

c PM3 refers to pollen mixture 3 including the pollen from C9, C58 and C63.

*, $\mathrm{P}<0.05$; ${ }^{* *}, \mathrm{P}<0.01 ;{ }^{* * * *}, \mathrm{P}<0.005 ;{ }^{* * * *}, \mathrm{P}<0.001$. 
a)

C65

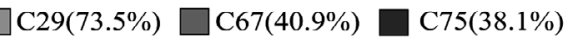

C38

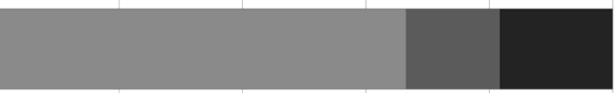

C5

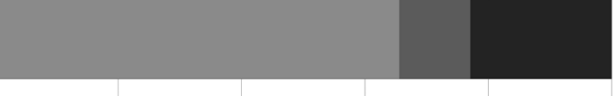

b)

C60

$\square \mathrm{C} 37(68.7 \%) \square \mathrm{C} 53(59.7 \%) \square \mathrm{C} 5(53.4 \%)$

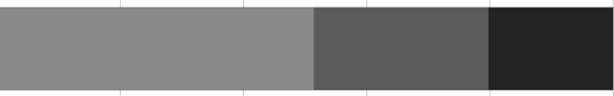

C6

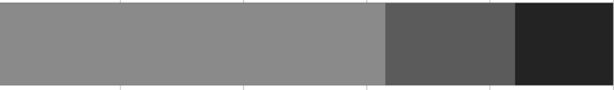

c)

$\square \mathrm{C} 29(73.5 \%) \square \mathrm{C} 67(40.9 \%) \square \mathrm{C} 75(38.1 \%)$

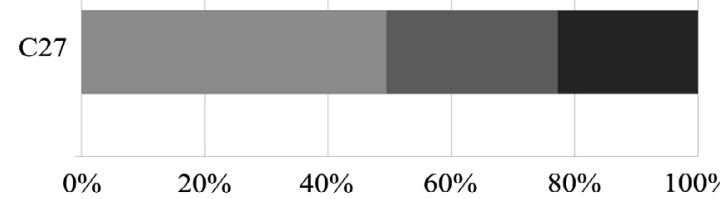

Figure 1. - The percentage of progeny assigned to each paternal parent in polycross-1 (a), polycross-2 (b) and polycross-3 (c). The values within parentheses are the pollen germination rate (\%) of paternal parents. The two pollinations, C52 x pollen mixture3 and C54 x pollen mixture3, were excluded because the number of seeds produced was too low to analyze statistically.

tions (Fig. 1, Table 1). Therefore, the variation in pollen germination rate may affect paternal contribution in polycrosses of C. japonica (Table 3, Fig. 1); however, we did not observe the pollen-tube growth, nor any pollenpollen interactions and selection in the postzygotic process. WHEELER et al. (2006) reported that pollen germination rate did not control paternal contribution in Populus spp.; however, they only recorded small differences in pollen germination rates between the pollen donors used in their polycrosses as a result of low pollen germination rates ( $<25 \%$ in all paternal donors).

Generally, an unequal paternal contribution in polycross designs leads to biased maternal GCA estimates. However, KumAR et al. (2007) reported that GCA estimates obtained from polycrosses were similar to those from female-tester mating designs. In their study, unequal paternal contribution was detected only in some families. Therefore, they suggested that precise GCA estimates could be obtained from polycrosses when paternal contributions only differed by a small amount. To obtain reliable GCA estimates from polycrosses in C. japonica, more equal paternal contribution is required. KUMAR et al. (2007) also suggested that polycrosses should make use of a large number of pollen donors in order to validate results, since large deviations from equal paternal contribution have been detected when using three or four pollen donors for Pinus radiata (MoRAN and GRIFFIN, 1985) and Picea abies (SKRøPPA and LINDGREN, 1994). In contrast, small deviations from equal paternal contribution have been detected when using more than nine pollen donors for Picea abies (SCHOEN and CHELIAK, 1987) and Pinus radiata (KUMAR et al., 2007). Therefore, using a large number of pollen donors (KUMAR et al. (2007) recommended more than 15) in a polycross might decrease the variations in the level of paternal contribution. The use, in polycrosses, of pollen-donor clones with similar pollen germination rates is an alternative method, but this is technically difficult for artificial crosses.

Though clone no. 53 contributed disproportionately with clone no. 6 according to the pollen flow in a seed orchard (accounting for about $47 \%$ of the total fertilization) (MoRIGUCHI et al., 2007), this was not demonstrated in the current work. NIKKANEN et al. (2000) reported a significant genotype-year interaction in pollen viability, which might account for our result. A specific investigation into the effect of pollen viability on paternal contributions in seed orchards is expected in the future study.

\section{Acknowledgements}

This work was partly supported by Research Fellowships from the Japan Society for the Promotion of Science for Young Scientists and Grant-in-Aid (Development of Technologies for Control of Pollen Production by Genetic Engineering) from the Forest Agency of Japan. The authors thank T. YAMADA for his helpful comments regarding pollen germination in $C$. japonica.

\section{References}

Apsit, V. J., R. R. NAKAmuRA and N. C. WheEleR (1989): Differential male reproductive success in Douglas-fir. Theor Appl Genet 77, 681-684.

Aronen, T., T. Nikkanen, A. Harju, H. Timmonen and H. HÄGGMAN (2002): Pollen competition and seed-siring success in Picea abies. Theor Appl Genet 104, 638-642.

Itoya, Y., T. Furukoshi, R. KIKUChI and K. NAGAsAKA (1978): Selective fertilization of Sugi plus tree. Ann Bull Kanto For Tree Breed Inst 14, 118-127. (in Japanese with English summary).

Kumar, S., S. Gerber, T. E. Richardson and L. Gea (2007): Testing for unequal paternal contributions using nuclear and chloroplast SSR markers in polycross families of radiata pine. Tree Genet Genomes 3, 207-214.

MorAN, G. F. and A. R. GRIFFIN (1985): Non-random contribution of pollen in polycrosses of Pinus radiata D. Don. Silvae Genet 34, 117-121.

Moriguchi, Y., H. Iwata, T. Ihara, K. Yoshimura, H. Taira and Y. TSumura (2003): Development and characterization of microsatellite markers for Cryptomeria japonica D. Don. Theor Appl Genet 106, 751-758. 
Moriguchi, Y., N. TANi, H. TAIRA und Y. Tsumura (2004): Variation of paternal contribution in a seed orchard of Cryptomeria japonica D. Don determined using microsatellite markers. Can J For Res 34, 1683-1690.

Moriguchi, Y., S. Tsuchiya, H. Iwata, S. Itoo, N. Tani, H. TAIRA and Y. TsumURA (2007): Factors influencing male reproductive success in a Cryptomeria japonica seed orchard revealed by microsatellite marker analysis. Silvae Genet 56, 207-214.

MurRAY, M. and W. F. THOMPSON (1980): Rapid isolation of high molecular weight plant DNA. Nuc Acids Res 8, 4321-4325.

Nakamura, R. R. and N. C. Wheeler (1992): Pollen competition and paternal success in Douglas-fir. Evolution 46, 846-851.

Nikkanen, T., T. Aronen, H. HägGman and M. VenäläINEN (2000): Variation in pollen viability among Picea abies genotypes-potential for unequal paternal success. Theor Appl Genet 101, 511-518.

OHBA, K., M. IWAKAWA, U. OKADA and M. Murai (1971): Paternal transmission of a plastid anomaly in some reciprocal cross of Sugi, Cryptomeria japonica D. Don. Silvae Genet 20, 101-107.

ОнвА, K. (1972): Study of selective fertilization using the pollen of Wagon-Sugi. Proc J Jap For Soc 83, 204-206. (in Japanese).

Parantainen, A. and H. L. Pasonen (2004): Pollen-pollen interactions in Pinus sylvestris. Scand J For Res 19, 199-205.

Pasonen, H. L., P. Pulkkinen, M. Käpylä and A. Blom (1999): Pollen-tube growth rate and seed-siring success among Betula pendula clones. New Phytol 143, 243-251.

Rogers, D. L. and T. J. B. Boyle (1991): Unequal paternal contributions in black spruce polycross seedlots. Heredity $67,373-379$.

Saito, M. and C. Yамамото (1977): The life span of some Japanese conifer pollen under room temperature. J Jap For Soc 59, 33-35 (in Japanese).
Schoen, D. J. and W. M. Cheliak (1987): Genetics of the polycross. 2. Male fertility variation in Norway Spruce, Picea abies (L.) Karst. Theor Appl Genet 74, 554-559.

Seido, K., K. Yamagishi, K. Ida, H. Murakami and S. ShIRAISHI (2000): Investigation of selective fertilization in hinoki (Chamaecyparis obtusa) using a chloroplast DNA marker. J Jap For Soc 82, 380-383 (in Japanese with English summary).

SkRøPPA, T. and D. LINDGREN (1994): Male fertility variation and nonrandom segregation in pollen mix crosses of Picea abies. Forest Genet 1, 13-22.

SNow, A. A. and T. P. SPIRA (1996): Pollen-tube competition and male fitness in Hibiscus moscheutos. Evolution 50, 1866-1870.

Spira, T., A. A. Snow and M. N. Puterbaugh (1996): The timing and effectiveness of sequential pollinations in Hibiscus moscheutos. Oecologia 105, 230-235.

TANI, N., T. TAKAHASHI, T. UJINO-IHARA, H. IWATA, K. Yoshimura and Y. Tsumura (2004): Development and characteristics of microsatellite markers for sugi (Cryptomeria japonica D. Don) from microsatellite enriched libraries. Ann For Sci 61, 569-575.

Tsumura, Y., K. Yoshimura, N. Tomaru and K. Ohba (1995): Molecular phylogeny of conifers using RFLP analysis of PCR-amplified specific chloroplast genes. Theor Appl Genet, 91, 1222-1236.

WeIR, B. S. (1996). Genetic Data Analysis II (pp. 209-211). Sinauer Assoc., Sunderland, Mass.

Wheeler, N., P. Payne, V. Hipkins, R. SAich, S. Kenny and G. TUSKAN (2006): Polymix breeding with paternity analysis in Populus: a test for differential reproductive success (DRS) among pollen donors. Tree Genet Genomes 2, 53-60.

Wiselogel, A. E. and J. P. van BuiJTEnen (1988): Probability of equal mating in polymix pollinations of loblolly pine. Silvae Genet 37, 184-187.

ZOBEL, B. J. and J. T. TALBERT (1984): Genetic testing programs. In Applied forest tree improvement (pp. 231-267). Wiley, New York. 